\title{
Pneumatic Colorectal Injury Caused by High Pressure Compressed Air
}

\author{
Jin Young Lee ${ }^{1}$, Young Hoon Sul ${ }^{1,2}$, Seung Je Go ${ }^{1}$, Jin Bong Ye ${ }^{1}$, Jung Hee Choi ${ }^{3}$ \\ ${ }^{1}$ Department of Trauma Surgery, Chungbuk National University Hospital, Cheongju; ${ }^{2}$ Department of Trauma Surgery, College of Medicine, \\ Chungbuk National University, Cheongju; ${ }^{3}$ Department of Anesthesiology and Pain Medicine, Chungbuk National University Hospital, \\ Cheongju, Korea
}

The pneumatic colorectal injury caused by high pressure compressed air are rare and can be fatal. Herein, we present a case of 45-year-old male who developed sudden onset of severe abdominal pain after cleaning the dust on his pants with high pressure compressed air gun dust cleaner. Emergent exploratory laparotomy was done which findings are a huge rectal perforation with multiple serosal and subserosal tear in sigmoid to splenic flexure of colon. Anterior resection with left hemicolectomy, and temporary transverse colostomy was performed. Postoperative course was uneventful. Recently, prognosis is generally favorable because of prompt diagnosis and emergent surgical management.

Keywords: Colon; Rectum; Pneumatic injury; Perforation; High pressure compressed air

\section{INTRODUCTION}

Because the use of high pressure compressed air has increased in many work places, the risk of associated pneumatic injuries is also increasing. Most pneumatic colorectal injuries usually occur when the air hose is directly inserted into the anus as a practical joke [1]. However, pneumatic colorectal injury can occur without inserting the air hose into the anus, and the perineal blasting with high pressure compressed air can penetrate barriers such as clothes and the anal sphincter, which can cause colorectal injuries either with or without perforation $[1,2]$. We present the case of a 45-year-old male who developed sudden onset of severe abdominal pain after cleaning the dust on his pants with a high pressure compressed air gun dust cleaner.

Received: June 15, 2018 - Accepted: August 9, 2018

Correspondence to: Young Hoon Sul, M.D.

Department of Trauma Surgery, College of Medicine, Chungbuk National

University, 776 1Sunhwan-ro, Seowon-gu, Cheongju 28644, Korea

Tel: +82-43-269-7847, Fax: +82-43-269-7810,E-mail: ssulyh@gmail.com ORCID code: https://orcid.org/0000-0003-3184-3396

(C) 2019 The Korean Society of Coloproctology

This is an open-access article distributed under the terms of the Creative Commons Attribution NonCommercial License (http://creativecommons.org/licenses/by-nc/4.0) which permits unrestricted noncommercial use, distribution, and reproduction in any medium, provided the original work is properly cited.

\section{CASE REPORT}

This study was approved by the Institutional Review Board (IRB) of Chungbuk National University Hospital and informed consent was waived by the IRB. A 45-year-old male who developed sudden onset of severe abdominal pain was admitted to the emergency department. A few hours previously, he reported that he had cleaned the dust on his pants with a high pressure compressed air gun, and his friends placed the air nozzle too close to his buttocks as a practical joke. The patient had severe lower abdominal pain that progressed to the whole abdomen, and had abdominal distension and hematochezia. On physical examination, the abdomen was markedly distended, with generalized tenderness and rebound tenderness. The erect chest X-rays (Fig. 1) showed a marked presence of pneumoperitoneum and transverse colon dilatation. A small amount of bloody stool gushed out, on digital rectal examination. He was hemodynamically stable with a blood pressure of $150 / 70 \mathrm{mmHg}$, heart rate of 84 beats/min, respiratory rate of 28 breaths $/ \mathrm{min}$ and body temperature of $35.5^{\circ} \mathrm{C}$. Laboratory tests showed mild leukocytosis which was seen as a white blood cell count $11.13 \times 10^{3} / \mu \mathrm{L}$, and otherwise showed no specific findings. On abdominal and pelvic computed tomography (APCT), a focal wall defect was seen at the rectum with abundant fecal material in the pelvic cavity (Fig. 2A), and multiple subserosal pneumotosis was seen from the descending to distal 
$\begin{aligned} \text { Annals of } & \text { Pneumatic Colorecta } \\ \text { Coloproctology } & \text { Jin Young Lee, et al. }\end{aligned}$

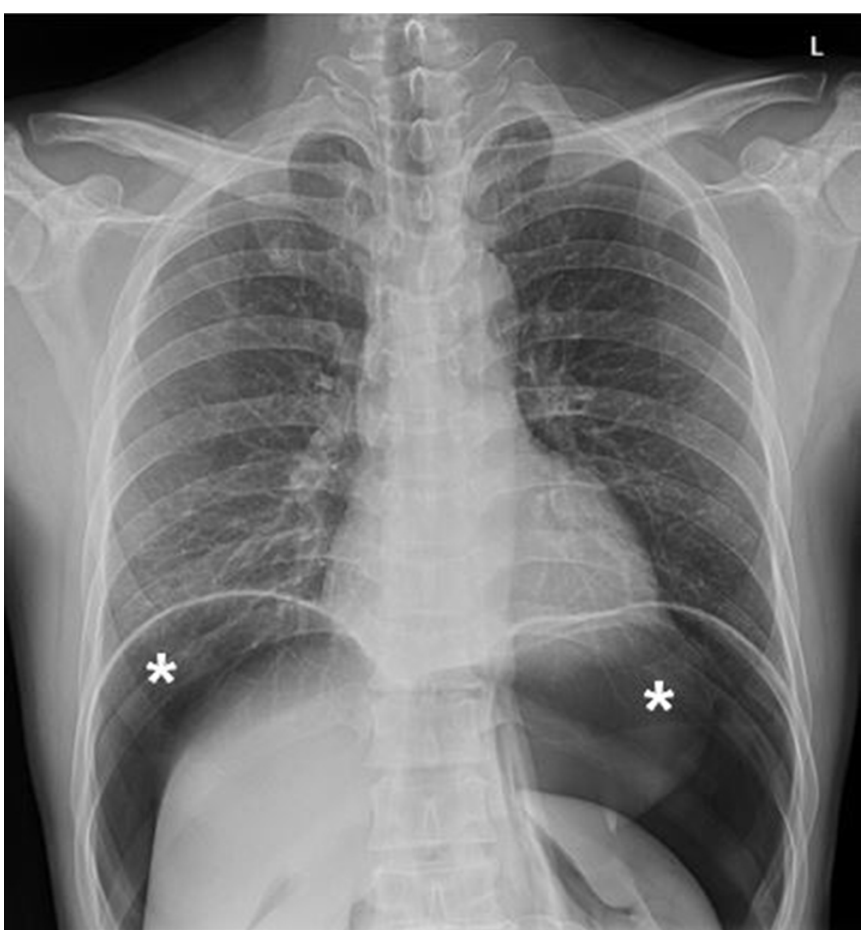

Fig. 1. Chest anteroposterior showing extensive free air (white asterisks) in the subphrenic area.

transverse colon with extensive pneumoperitoneum (Fig. 2B).

An emergent exploratory laparotomy was performed under general anesthesia in the supine position. On opening the abdomen, a large amount of air gushed out and a large amount of fecal material was found. A longitudinal, $10 \mathrm{~cm}$, full-thickness perforation at the rectum was seen at $5 \mathrm{~cm}$ above the peritoneal reflection. Multiple subserosal tears were seen in the sigmoid colon and descending colon, and an approximately $15-\mathrm{cm}$-sized serosal and muscle layer tear was seen in the splenic flexure of the colon (Fig. 3). Anterior resection with a left hemicolectomy, and temporary colostomy of the transverse colon was decided as the best treatment approach. The postoperative course was uneventful, and he was discharged on the 12th day postoperatively.

\section{DISCUSSION}

Pneumatic colon injuries have been reported historically, first by Stone in 1904 [3], and similar cases have been reported sporadically. These injuries are generally caused by industrial injury, and primarily occur as a result of practical jokes [4]. As mentioned earlier, pneumatic colorectal injury can occur without inserting the air hose into the anus. High pressure compressed air can form a column, which acts like a solid body, which forces the anal sphincter open [5]. The compressed air concentrated around the anus can easily be delivered through the anus, because of the funnel-shaped anatomical structure of buttocks. Therefore, the com-
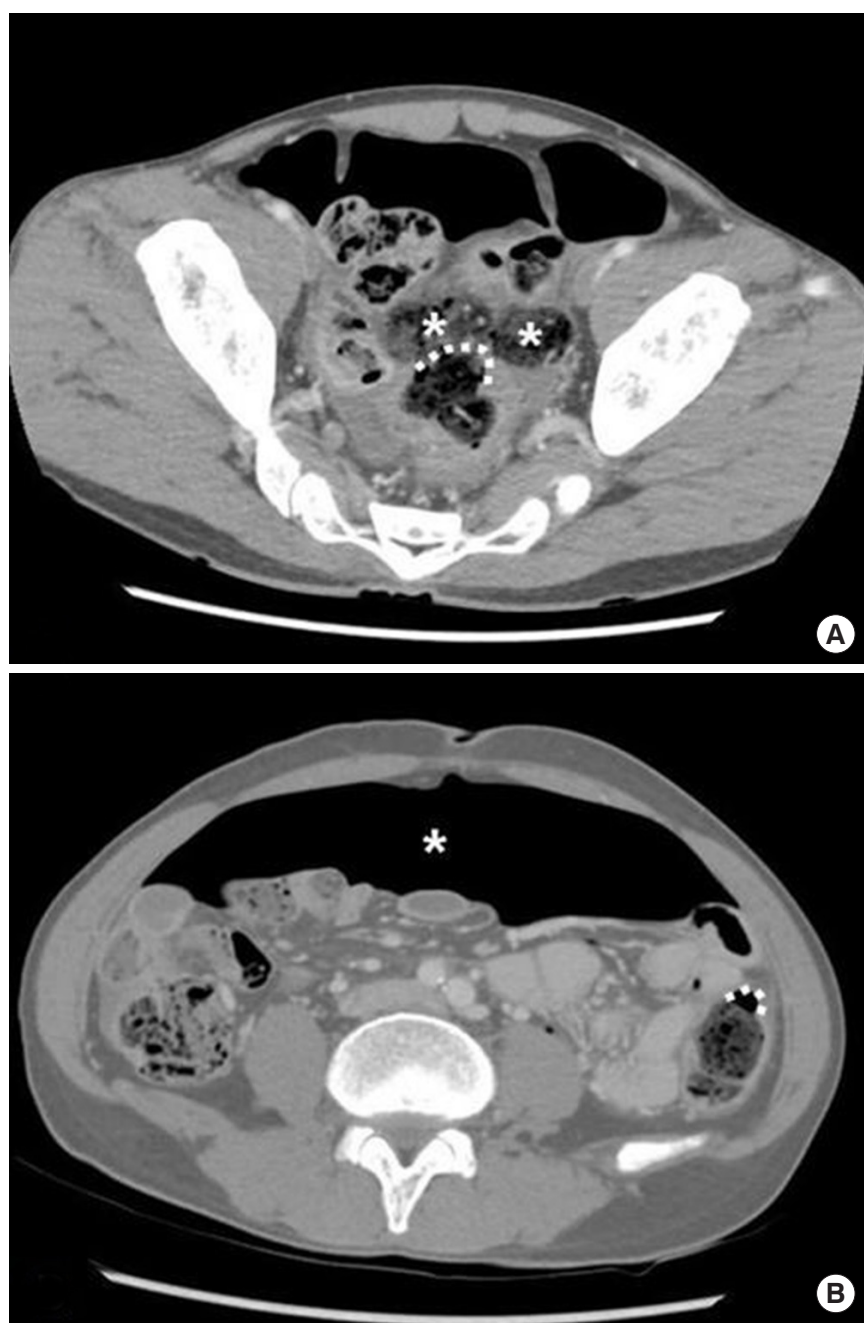

Fig. 2. Computed tomography findings. (A) Wall defects (white dots) were seen at the rectum with abundant fecal material (white asterisks) in the pelvic cavity. (B) Extensive free air on peritoneal cavity (white asterisk) and Subserosal pneumotosis (white dots) on descending colon was seen.

pressed air could easily pass through clothes, and even the anal sphincter, and then cause colorectal injury [1].

The normal colon can withstand high intraluminal pressure before rupture occurs. When pressure progressively increases, serosal tear occurs first, followed by the muscle and the mucosa $[6,7]$. Colonoscopic studies have found that the intraluminal pressure required to perforate the colon was greater than $0.109 \mathrm{~kg} / \mathrm{cm}^{2}$ (1.547 psi/80 $\mathrm{mmHg}$ ) [8]. In the cadaveric sigmoid colon, a serosal tear can occur with a pressure of $0.27 \pm 0.02 \mathrm{~kg} / \mathrm{cm}^{2}(3.9 \pm 0.29$ psi $/ 202 \pm 15 \mathrm{mmHg}$ ), and a mucosal rupture can be caused by pressure of $0.307 \pm 0.019 \mathrm{~kg} / \mathrm{cm}^{2}(4.32 \pm 0.271 \mathrm{psi} / 226 \pm 14$ $\mathrm{mmHg}$ ) following colonoscopic insufflations [9]. In industrial fields, highly compressed air over $10 \mathrm{~kg} / \mathrm{cm}^{2}$, is widely used which is greater than the pressure needed for intestinal perforation [1]. 

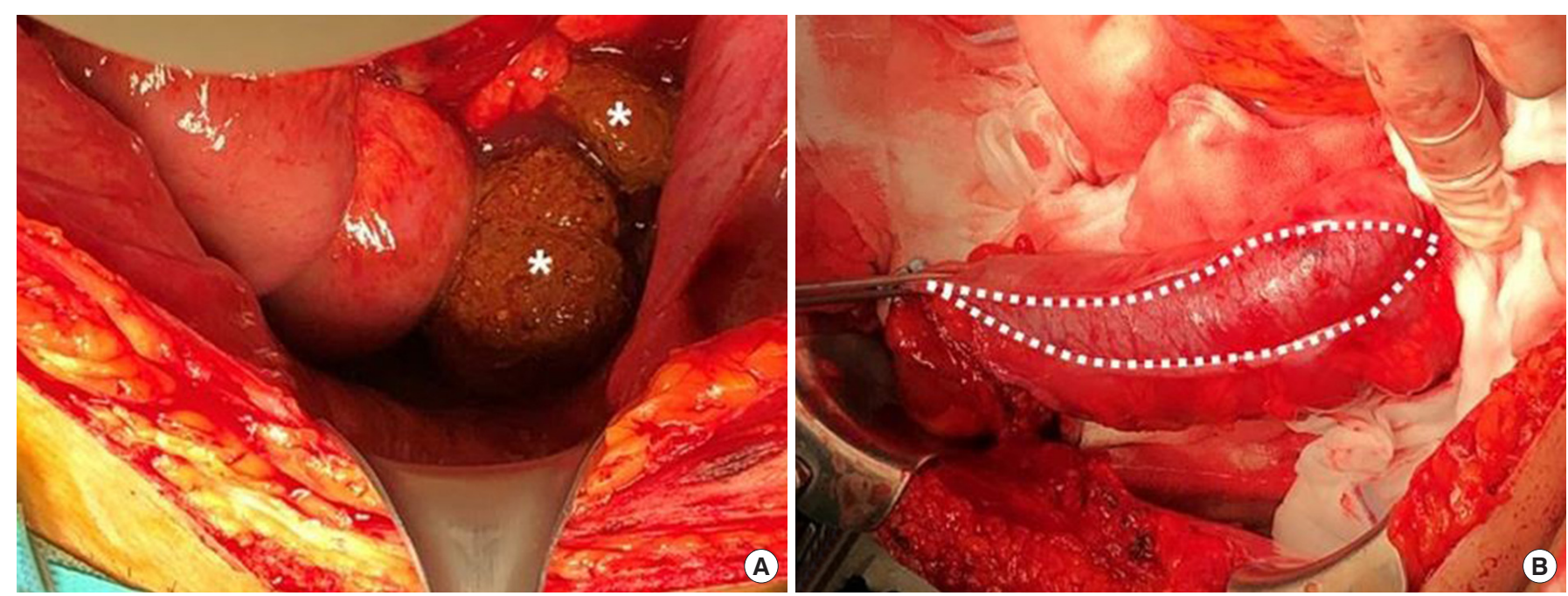

Fig. 3. Operative findings. (A) A large amount of fecal material (white asterisks) was found in the pelvic cavity due to rectal perforation. (B) Longitudinal serosal tear of the left colon (white dots).

Severe abdominal distension, pain, and peritoneal signs such as abdominal rigidity, tenderness, and rebound tenderness are common clinical manifestations [10]. The diagnosis is usually straightforward because the patient typically has a history of abdominal pain and distension after exposure to compressed air. In addition, a distended colon or a large amount of free air in the peritoneal cavity could be observed by chest or abdominal radiologic examinations [1]. This patient also complained of abdominal distension, pain, peritoneal signs, and a large amount of free air. Although the patient exhibited tachypnea (respiratory rate 28 breaths/min), other vital signs were stable. Tension pneumoperitoneum may cause respiratory distress and hemodynamic instability. Percutaneous decompression with a needle or cannula may be useful for relieving tension pneumoperitoneum $[6,10]$.

The anal canal and distal rectum are well-supported by external structures including the endopelvic fascia, or pelvic diaphragm. The rectosigmoid region is the first part of the colon that is impacted by a column of air [2]. Therefore, most reported injuries occur in the rectosigmoid junction, sigmoid colon, and sigmoiddescending junction $[2,6,7]$. We performed APCT before surgical exploration to determine the specific colon injury locations. Unlike previous reports, the perforation was seen in the rectum; however, multiple serosal, mucosal tears were seen in the sigmoid to distal transverse colon. Treating colon perforation is dependent on the extent of contamination [10]. Recently, primary repair of all colorectal injuries has been supported by research studies [11, 12]. However, there is still a debate about the options for primary repair or diversion. At the laparotomy for this case, primary repair was not appropriate because of the length of perforation, multiple subserosal tears, and severe fecal contamination. However, for similar cases the prognosis has generally been favorable in recent reports when early surgical management is performed $[1,2,7]$.

\section{CONFLICT OF INTEREST}

No potential conflict of interest relevant to this article was reported.

\section{REFERENCES}

1. Park YJ. Rectal perforation by compressed air. Ann Surg Treat Res 2017;93:61-3.

2. Yin WB, Hu JL, Gao Y, Zhang XX, Zhang MS, Liu GW, et al. Rupture of sigmoid colon caused by compressed air. World J Gastroenterol 2016;22:3062-5.

3. Stone GW. Rupture of the bowel caused by compressed air. Lancet 1904;2:216.

4. Waugh RL, Leonard FC. Rupture of the colon due to compressed air, with particular reference to the character of the lesion. Mil Surg 1951;108:294-301.

5. Andrews EW. Pneumatic rupture of the intestine or new type of industrial accident. Surg Gynecol Obstet 1911;12:63-4.

6. Kim SJ, Ahn SI, Hong KC, Kim JS, Shin SH, Woo ZH. Pneumatic colonic rupture accompanied by tension pneumoperitoneum. Yonsei Med J 2000;41:533-5.

7. Sy ED, Chiu YI, Shan YS, Ong RL. Pneumatic colon injury following high pressure blow gun dust cleaner spray to the perineum. Int J Surg Case Rep 2015;6C:218-21.

8. Woltjen JA. A retrospective analysis of cecal barotrauma caused by colonoscope air flow and pressure. Gastrointest Endosc 2005; 61:37-45.

9. Brayko CM, Kozarek RA, Sanowski RA, Howells T. Diverticular rupture during colonoscopy. Fact or fancy? Dig Dis Sci 1984;29: 427-31.

10. Huang CW. Barotrauma of the colorectum caused by high-pres- 


\section{Coloproctology Jin Young Lee, et al.}

sure compressed air: a case report. J Taiwan Emerg Med 2009;11: 67-70.

11. Brown CV, Teixeira PG, Furay E, Sharpe JP, Musonza T, Holcomb J, et al. Contemporary management of rectal injuries at level I trauma centers: the results of an American Association for the
Surgery of Trauma multi-institutional study. J Trauma Acute Care Surg 2018;84:225-33.

12. Steele SR, Maykel JA, Johnson EK. Traumatic injury of the colon and rectum: the evidence vs dogma. Dis Colon Rectum 2011;54: 1184-201. 